\title{
Regulation of food intake
}

\section{By F. R. BELL, Department of Medicine, Royal Veterinary College, University of London, London $N W \mathrm{I}$}

Knowledge appertaining to the regulation of food intake in animals generally, and in particular information concerning mammals, is probably applicable to the pig. It is necessary to make this proviso in the context of this symposium on the quantitative aspects of pig nutrition, for in reviewing the subject I have the impression that so far the physiologist has been somewhat backward in providing sufficient basic scientific facts for the nutritionist to build on. Most of the anatomical, physiological, behavioural, biochemical and pharmacological studies which provide information on the regulation of food intake have been derived from experimental studies in the rat, man and ruminants. In spite of this lack a great deal has been accomplished by the porcine nutritionist.

In this brief review I shall attempt to confine myself mainly to data obtained from the pig and not to compromise data which I believe will be presented by other contributors to this symposium.

The basic morphological structure of the alimentary tract and its associated glands, its polarity from stomodeum to proctodeum, its neurendocrine control and its relationship with other parts of the body was laid down in phylogeny to provide a pattern for all mammals. The great basic patterns of alimentary digestion and nutrition are, therefore, referable to the pig. There are, however, clear differences arising from the special ecological evolution of the pig which have persisted into subsequent domestication and which are seen today as special porcine behavioural characteristics.

For this symposium I do not intend to attempt to consider the whole area of investigation wherein knowledge of the regulation of food intake has accumulated. Those interested in greater detail, especially in the role of the hypothalamus in control of food intake, will find references in a recent review (Bell, 1971). In Fig. I a schema showing the various systems of control which react together to regulate food intake is presented, and emphasizes the feedback from the alimentary tract to modulate the central nervous genesis of behavioural activity towards food intake.

It will be appreciated that 'regulation' and 'control' are not alternatives. Brobeck (1960) has argued that regulation should be used to indicate the continuing maintenance of a steady state through physiological mechanisms which themselves depend upon special receptors able to detect change in the steady state itself. Control, on the other hand, is the management of a rate of functioning. In the present discussion control of food intake together with the control of heat loss and work output regulate the energy content of the whole porcine body, or some part of the content, which to the nutritionist is preferably a rising increment of muscle. 


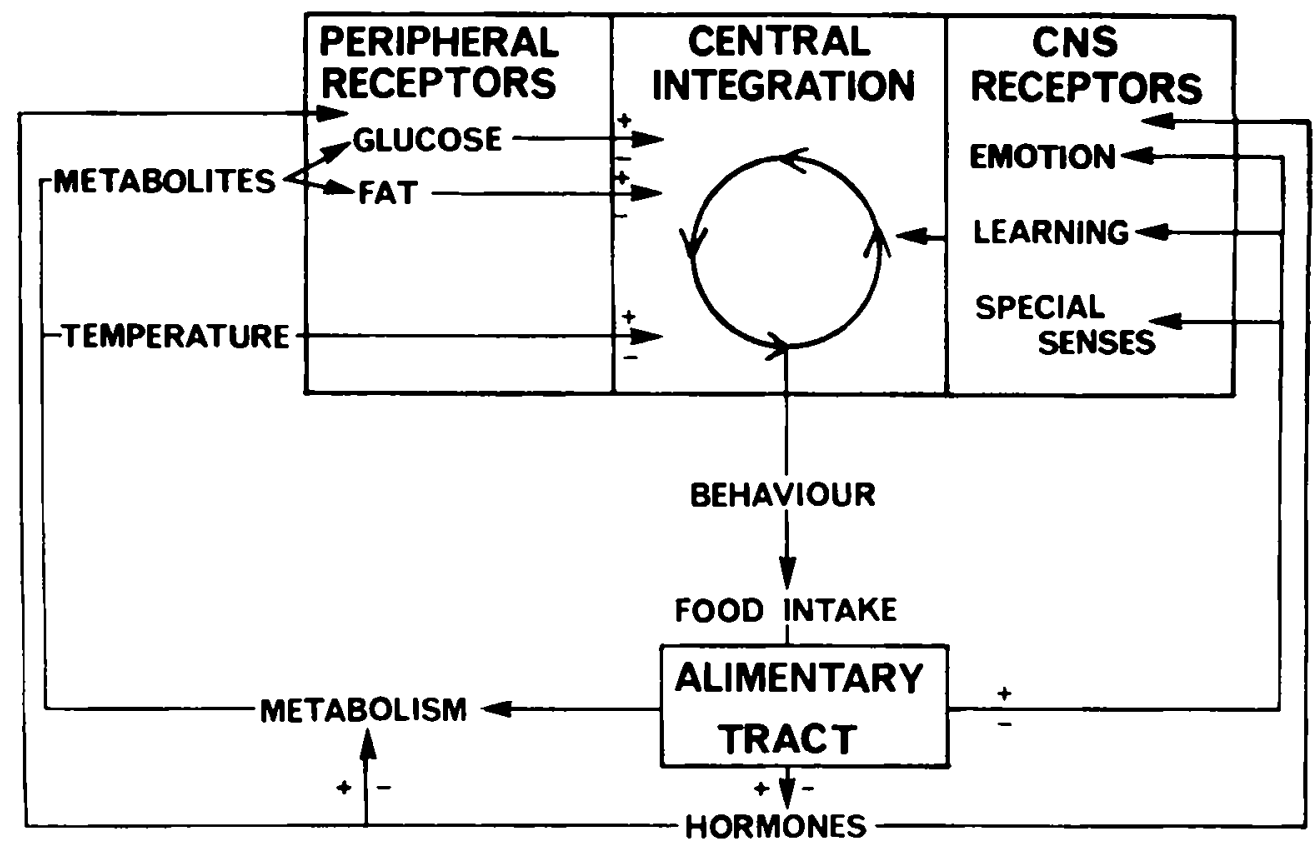

Fig. 1. Schema showing correlation of the control systems which regulate food intake. The central integration is probably brought about by the effects of neurotransmitters generated by a variety of sources on the metabolism of neurones. + , Stimulating effect; - , inhibitory effect.

Thermoreceptors occur both centrally in the brain and peripherally in the skin and the liver. Decrease or increase of the input from these receptors, especially to the diencephalon and limbic region of the brain, are important in regulating the energy stores in the body to maintain a constant body temperature. It is becoming apparent that thermoregulatory control is mediated by neurones with special receptors interacting with a great variety of neurotransmitters which themselves are influenced by enzymes. Brobeck ( 1960 ) regards thermoregulation of the body as fundamental in the regulation of food intake and Ingram \& Legge (1974) have shown this to be so in the pig.

Glucoreceptors are cells which are sensitive to dynamic change in glucose availability. Mayer ( 1953 ) defends a glucostatic control of food intake since the ventral median nuclei of the hypothalamus contain cells with an affinity for gold thioglucose. It must be noted, however, that the ventral median nuclei can be ablated electrically without effect on food intake. There are also glucoreceptors in the liver and pancreas, and probably in the intestine, which produce discharges in afferent nerves on changes in blood glucose levels. Kennedy (1966) has suggested that cells which are sensitive to the level or availability of fat or the metabolites of fat may provide a lipostatic control of food intake, the glucoreceptors dealing with shortterm control. Stephens \& Baldwin (1974) failed to inhibit food intake in pigs by intravenous injection of glucose or amino acids. 
Newborn pigs deprived of food for $72 \mathrm{~h}$ die of starvation as the high birth liver glycogen content falls, but pigs of even a few days of age resist hypoglycaemic starvation. The reason for this age difference is unknown but failure of gluconeogenesis has been implicated (Swiatek, Kipnis, Mason, Chao \& Cornblath, 1968). Immaturity of central cellular receptor mechanisms may play a part but it is more likely that imbalance of behavioural interplay between piglet and sow deprives the newborn animal of its food supply.

The sum of the responses of special receptors together with input from the special senses and learned conditioned responses produces a total effect seen as a behavioural reaction towards the ingestion of food. The behavioural reaction is often a learned response which is absent or less well developed in neonatal animals so that they are dependent for signals from the dam. Such vocal signals are particularly well developed in sows.

The activation of the anterior teats reinforces nursing behaviour and stimulates milk let-down (Fraser, 1973). A pattern of hourly suckling becomes established which appears to be controlled by mechanoreceptors in the stomach, for in 7-d-old piglets the stomach is emptied in less than I. 5 h. Stephens (1975) has shown that preloading the stomach substantially reduced voluntary milk intake but vigorous oral sucking activity on the other hand was not suppressed by gastric distension, suggesting that sucking is not inhibited by satiation.

Social interaction which affects food intake is important in older pigs and apparently is dependent upon sensory systems. This aspect of behaviour is discussed by Ewbank, Meese \& Cox (1974), who concluded that sight was not a factor but pheromones might be more important. The strong drive to suck seen in young pigs may persist in older groups and could be the trigger mechanism for tail biting and other mutilation procedures seen frequently in pig husbandry.

Signals from the alimentary tract, especially from the stomach and small intestine, affect gastric emptying and thus inversely the intake of food. The exponential emptying of food from the stomach of the pig is similar in pattern to that described for other animals (Braude, Newport \& Porter, 1970). Isotonic saline appears to be an adequate stimulus in the pig which suggests that control of gastric emptying in the pig is mediated through duodenal osmoreceptors. In the calf, gastric distension and resultant emptying is controlled by mechanisms with afferent pathways in the vagus nerves, but inhibition of gastric emptying is associated with hormone production which is unaffected by vagotomy (Bell \& Watson, 1976). The inhibitory hormones appear to be motilin and secretin from the intestine but the site of action is not known. The fact that intravenous infusion of pentagastrin inhibits gastric motility and reduces gastric emptying suggests that the effect may be peripheral, possibly by direct binding of the hormone to the gastric musculature or through some cellular neurotransmitter receptor (Bell, Titchen \& Watson, I976).

It has been shown recently in man that gastric emptying may be controlled by the nutrient density of the gastric chyme passing to the duodenum (Hunt \& Stubbs, 1975). Furthermore a relationship has been established between bodyweight and gastric and intestinal handling of energy loading in man (Johansson, 35 (1) 5 
1974). The presence of digested food in the duodenum triggers mechanisms which inhibit emptying of the stomach but food energy transfer rates were higher in heavy than light subjects. The intestinal transit time was more rapid in heavy subjects so that no more food energy was absorbed and more unabsorbed food passed to the lower parts of the intestine. Although Freeman, Noakes, Annison \& Hill ( 1968 ) have shown that it is unlikely that absorptive capacity of the intestine ever limits assimilation in the young pig, further studies might provide information on the control of food intake and possibly on the nutrition of the pig.

The development of radioimmunoassay has revealed the presence of many 'new' polypeptides which can be released from secretory cells in the alimentary tract by the products of digestion. The disposition and amount of these hormones vary with the species, and the pig, as well as providing gastrin and secretin, is a source of motilin, vasoactive intestinal polypeptide, enteroglucagon and gastric inhibitory polypeptide. These hormones affect gastrointestinal motility and secretion. There is a similarity in the metabolism of these hormones to catecholamines and there is an affinity in their metabolism with other endocrine glands such as the thyroid, parathyroid and adrenal cortex. Further work may show feedback relationships with the central nervous system and the alimentary tract such as that shown already by some hormones and many neurotransmitters. Fitzsimmons \& Setler (1975) have already shown that thirst is increased by angiotensin and by cholinergic systems but is not inhibited by adrenergic antagonists, whereas dopamine is an important participant in angiotensin drinking-drive.

Food intake shows cycles of activity in most species and an hourly cycle has been mentioned in the suckling pig. Axelrod (1974) has shown that circadian rhythms occur with the formation of serotonin and melatonin in the pineal gland and that the metabolic syntheses which occur in the dark are abruptly abolished by exposure to light. These rhythms occur with diurnal changes in the release and binding of the neurotransmitter noradrenaline from sympathetic neurones terminating on the pineal. The generation of pineal amines appears to arise from $a$ 'biological clock' present in or near the suprachiasmatic nucleus of the hypothalamus, modulated by an inhibitor generated by environmental light. This type of mechanism might be of great interest in the control of food intake, for oral melatonin has already been shown in man to elevate serum growth hormone levels (Smythe \& Lazarus, 1974). Other rhythms such as that of the oestrus cycle which affects food and water intake might be controlled by similar processes involving central neurotransmitters such as glycine, dopamine, as well as catecholamines and cholinergic agonists and antagonists.

In reviewing the regulation of food intake the importance of the diencephalon and limbic brain should be again emphasized for these neurones are intimately related with vegetative mechanisms such as thermoregulation, sleep and nursing. Furthermore, trophic hormones released through the pituitary link other endocrine glands with local hormones of the alimentary tract to control digestion and absorption, which is the final consummatory event of food control which maintains the regulation of homeostasis. It is probable that radioimmunoassay and electron-microscopy and the newer techniques of biochemistry, pharmacology and 
immunology will provide the tools for a more rigid analysis of the food control mechanisms in the near future. These data will provide the facts which can then be utilized by the nutritionist.

The original work mentioned in this paper was supported by the Agricultural Research Council.

\section{REFERENCES}

Axelnod, J. (1974). Science, N.Y. 184, 134 r.

Bell, F. R. (1971). Proc. Nutr. Soc. 30, 103.

Bell, F. R., Titchen, D. A. \& Watson, D. J. (1976). Y. Physiol., Lond. 251 , I 2 .

Bell, F. R. \& Watson, D. J. (1976). Proc. sth int. Symp. Gastroent., Leween.

Braude, R., Newport, M. J. \& Porter, J. W. G. (1970). Br. F. Nutr. $24,827$.

Brobeck, J. R. (1960). In Handbook of Physiology, Section I, Neurophysiology, vol. 2, p. I 197 [H. W. Magoun, editor]. Washington, DC: American Physiological Society.

Ewbank, R., Meese, G. B. \& Cox, J. E. (1974). Anim. Behav. 12, 923.

Fitzsimmons, J. T. \& Setler, P. E. (1975). F. Physiol., Lond. 250, 6r 3.

Fraser, D. (1973). Br. vet. F. 129, 324.

Freeman, C. P., Noakes, D. E., Annison, E. F. \& Hill, K. J. (Ig68). Br. J. Nutr. 22, 739.

Hunt, J. N. \& Stubbs, D. F. (1975). F. Physiol., Lond. 245, 209.

Ingram, D. L. \& Legge, K. F. (1974). Comp. Biochem. Physiol. 48A, 573.

Johansson, C. (1974). Scand. F. Gastroent. 9, Suppl. 28, I.

Kennedy, G. C. (1966). Br. med. Bull. 22, 216.

Mayer, J. (1953). Physiol. Reo. 33, 472.

Smythe, G. A. \& Lazarus, L. (1974). Science, N.Y. 184, 1373.

Stephens, D. B. (1975). F. comp. physiol. Psychol. 88, 796.

Stephens, D. B. \& Baldwin, B. A. (1974). Physiol. Behav. 12, 923.

Swiatek, K. R., Kipnis, D. M., Mason, G., Chao, K.-L. \& Comblath, M. (1968). Am. J. Physiol. 214,400 . 